\title{
Article \\ An Empirical Study for Real Options of Water Management in the Three Gorges Reservoir Area
}

\author{
Zuliang Lu ${ }^{1,2, *}$, Xiankui Wu ${ }^{1}$, Fei Cai ${ }^{1}$ and Fei Huang ${ }^{1}$ \\ 1 Laboratory for Nonlinear Science and System Structure, Chongqing Three Gorges University, \\ Chongqing 404000, China; xiankuiwu@126.com (X.W.); feicaizyy@126.com (F.C.); feihuangc@126.com (F.H.) \\ 2 Research Center for Mathematics and Economics, Tianjin University of Finance and Economics, \\ Tianjin 300222, China \\ * Correspondence: zulianglu@csrc.ac.cn
}

Citation: Lu, Z.; Wu, X.; Cai, F.; Huang, F. An Empirical Study for Real Options of Water Management in the Three Gorges Reservoir Area. Sustainability 2021, 13, 11255. https: / / doi.org/10.3390/ su132011255

Academic Editors: João Carlos de Oliveira Matias and Paolo Renna

Received: 18 July 2021

Accepted: 17 September 2021

Published: 12 October 2021

Publisher's Note: MDPI stays neutral with regard to jurisdictional claims in published maps and institutional affiliations.

Copyright: (c) 2021 by the authors. Licensee MDPI, Basel, Switzerland. This article is an open access article distributed under the terms and conditions of the Creative Commons Attribution (CC BY) license (https:// creativecommons.org/licenses/by/ $4.0 /)$.

\begin{abstract}
This paper investigates an empirical evaluation of water management on agricultural irrigation. To address this problem, a real options model was proposed. This model analysis the choice of investment in water savings. Also, the model discusses a linear complementary problem that can be transformed into the inequalities of parabolic variational. By using a power penalty method, we solved the parabolic variational inequalities. The results depicted that the nonlinear parabolic equations' solution is converges to the rate of order $O\left(h^{-\frac{k}{2}}\right)$. A numerical example is given at the end of the paper to demonstrate the theoretical analysis follows from the Three Gorges Reservoir Area.
\end{abstract}

Keywords: water management; Three Gorges Reservoir Area; water price

\section{Introduction}

Water resource security is recognized as one of the most severe challenges with which mankind is facing, especially in agriculture. There is a critically uneven distribution of water resources in agricultural irrigation water resources in China [1]. Per capital available water is bountiful in the south, but few in the north. The irrigation of China in water consumption needs not only large but also excess waste. Especially in the areas with abundant water resources [2], they possess no strong sense for saving water and have low utilization efficiency of irrigation water.

The Three Gorges Reservoir Area [3] is such a region we mentioned. Since the establishment of the Three Gorges Dam, it directly inundated the 682 square kilometers of the valley area and spread to 19 counties and cities with an area of 6 square kilometers. This leads to plenty of water resources with the poor ability of soil and water inadequate conservation in the Three Gorges Reservoir Area. Even, there have led to a significant decline in forest coverage because the hill slope area accounted for 97.3 percent of which the slope area over 30 degrees is more than half of the slope area, unreasonable farming practices on arable land and deforestation [4]. Affected by the flooding of the reservoir and the second occupation of land by immigrants, the per capita cultivated land area in the Three Gorges Reservoir Area decreased from 73 square meters to 60 square meters. So challenges are seriously confronted with the sustainable development of agriculture.

According to the survey [5], however, the current effective irrigation rate is only $25.9 \%$. The rest which depends on rains belongs to no irrigation facilities. Paddy field is the main part of the current irrigation areas, accounting for $47.3 \%$ of the total irrigation areas, but the only $59.6 \%$ of paddy fields can be irrigated, while only $16.4 \%$ of drylands and $19.5 \%$ of garden lands can be irrigated. The main source of irrigation water is small-scale water supply projects [6]. In the existing projects, pond reservoir is the main body of water supply, accounting for $62.3 \%$ of the total water supply capacity. Followed by reservoirs, accounting 
for $16.1 \%$, stone river weirs, cisterns, pumping stations, and spring weirs accounted for $10.6 \%, 2.92 \%, 2.68 \%$, and $1.28 \%$ in proper sequence.

The demand for freshwater in agriculture application is growing rapidly throughout the Three Gorges Reservoir Area. Although water-saving exercises have been developed to reduce irrigation application requirements and to improve growing conditions, a lot of water is wasted because of leaking enough irrigation systems [6]. Thus, it is imperative to enhance the effectiveness of irrigation and water conservation.

The large amount of water consumed in irrigation means every increase in efficiency can greatly reduce water consumption [7]. The effectiveness of agricultural water management in the area with plenty of water resources but a larger amount of water wasted needs suitable and efficient methods. But the indeterminacy on water, the price will influence irrigators on making decisions where they elect the timing of investment in the Three Gorges Reservoir Area. Therefore, we choose the real options method to manage problems of the decision making [8-13].

Water management relies on both the price of water and time. And the value of the European and American real option is determined by a linear complementarity problem [14]. By adopting the method of power penalty, to approximate the nonlinear parabolic equations [15], and we discuss it subsequently [16,17]. Accordingly, the uniqueness of the solution is obtained. Meanwhile, we show the the nonlinear parabolic equations' solution is converges to the rate of order $O\left(h^{-\frac{k}{2}}\right)$, where $h$ is the penalty number.

\section{Materials and Methods}

Time and water price are two crucial parameters on decision making problems [18]. Therefore, in this paper, we introduce the rules of a financial market into strategic investment decision-making. The stochastic result of water price can be presented via the geometric Brownian motion [19], thus we set $P_{t}$ is the water price, then it holds that

$$
d P_{t}=\alpha P_{t} d t+\sigma P_{t} d W
$$

where $W$ expresses the Brownian motion. The fluctuation of water price is constant and $V(P)$ which denotes the expected present value [10] is preset by

$$
V(P)=\frac{P a^{0}}{\delta}-\frac{Q}{\gamma}
$$

where $P$ denotes the water price, $a^{0}$ denotes water conservation via using new technologies, $Q$ denotes the direct cost, and $\delta$ denotes the discount rate.

Irrigators have the right opts to suspend making use of waters that spend more than operating costs and buy some necessary water in irrigation from the marketplace [12]. Hence the value of the project can be presented

$$
\frac{1}{2} \sigma^{2} P^{2} V^{\prime \prime}(P)+(\gamma-\delta) P V^{\prime}(P)-\gamma V(P)+\Gamma(P)=0,
$$

where $\Gamma(P)=\max \left\{P a^{0}-Q, 0\right\}$. After analysis, there holds that

$$
V(P)= \begin{cases}\beta_{1} P^{\mathcal{T}_{1},} & P a^{0}<Q, \\ \beta_{2} P^{\mathcal{T}_{2}}+\frac{P a^{0}}{\delta}-\frac{Q}{\gamma}, & P a^{0} \geq Q,\end{cases}
$$

where $\mathcal{T}_{1}$ and $\mathcal{T}_{2}$ can be gained by the quadratic equation as follows:

$$
\frac{1}{2} \sigma^{2} \mathcal{T}(\mathcal{T}-1)-(\gamma-\delta) \mathcal{T}-\gamma=0
$$

We introduce the expresses of $\beta_{1}$ and $\beta_{2}$, it holds that 


$$
\beta_{1}=\frac{Q\left(\frac{\mathcal{T}_{1}-1}{\delta}-\frac{\mathcal{T}_{1}}{\gamma}\right)}{\mathcal{T}_{2}-\mathcal{T}_{1}}\left(\frac{Q}{a^{0}}\right)^{-\mathcal{T}_{1}}+Q\left(\frac{1}{\delta}-\frac{1}{\gamma}\right)\left(\frac{Q}{a^{0}}\right)^{-\mathcal{T}_{1}}
$$

and

$$
\beta_{2}=\frac{Q\left(\frac{\mathcal{T}_{1}-1}{\delta}-\frac{\mathcal{T}_{1}}{\gamma}\right)}{\mathcal{T}_{2}-\mathcal{T}_{1}}\left(\frac{Q}{a^{0}}\right)^{-\mathcal{T}_{2}} .
$$

We adopt dynamic programming method to evaluate real options, the investors can continue to wait or invest to get rewards

$$
F^{0}(P)=V(P)-I,
$$

If $\rho=\gamma$, then the real option value $[18,20]$ is giveing by :

$$
F(P, t)=\max \left\{F^{0}(P), \frac{1}{1+\rho d t} E_{t}[F(P+d P, t+d t) \mid P]\right\} .
$$

If

$$
F^{0}(P)>\frac{1}{1+\rho d t} E_{t}[F(P+d P, t+d t) \mid P]
$$

then we have

$$
F(P, t)=F^{0}(P),
$$

so

$$
F(P, t)>\frac{1}{1+\rho d t} E_{t}[F(P+d P, t+d t) \mid P] .
$$

thus we have

$$
\rho F(P, t) d t>E_{t}[d F(P, t)] .
$$

Combining with Ito's Lemma yields

$$
\rho F d t>\frac{\partial F}{\partial t} d t+\frac{1}{2} \sigma^{2} P^{2} \frac{\partial^{2} F}{\partial P^{2}} d t-\alpha P \frac{\partial F}{\partial P} d t .
$$

Then we obtain

$$
L F>0,
$$

we set the partial differential operator $L$

$$
L F=-\frac{\partial F}{\partial t}-\frac{1}{2} \sigma^{2} P^{2} \frac{\partial^{2} F}{\partial P^{2}}-\alpha P \frac{\partial F}{\partial P}+\rho F .
$$

Otherwise,

$$
F(P, t)=\frac{1}{1+\rho d t} E_{t}[F(P+d P, t+d t) \mid P]>F^{0},
$$

which means that

$$
L F=0 \text { and } F-F^{0}>0 .
$$

In brief, the partial differential complementarity problem is gained as follows: 


$$
\left\{\begin{array}{l}
L F \geq 0 \\
F-F^{0} \geq 0 \\
L F \cdot\left(F-F^{0}\right)=0
\end{array}\right.
$$

the boundary conditions is given by

$$
F(0, t)=0 \quad \text { and } \quad F\left(P_{\max }, t\right)=V\left(P_{\max }\right)-I,
$$

and the terminal condition

$$
F(P, t=T)=F^{0}(P) .
$$

Our goal is to find the best $P^{0}(t)$, it satisfies $F\left(P^{0}, t\right)=F^{0}\left(P^{0}\right)$ and $F^{\prime}\left(P^{0}\right)=\left(F^{0}\right)^{\prime}\left(P^{0}\right)$ are used to depict the exercise boundary [21].

\section{Results}

In order to facilitate theoretical analysis, we rewrite (6) as follows:

$$
L F=-\frac{\partial F}{\partial t}-\frac{\partial}{\partial P}\left(\varepsilon P^{2} \frac{\partial F}{\partial P}+\epsilon P F\right)+\vartheta F
$$

where $\varepsilon=\frac{1}{2} \sigma^{2}, \epsilon=\alpha-\sigma^{2}$, and $\vartheta=\rho+\alpha-\sigma^{2}$.

Next, an equivalent form that satisfies the same kind of Dirichlet boundary will apply for discussing convenience. But the first is to introduce a new function, namely, let $F_{0}(P)$ be a twice differentiable function, and there holds

$$
u(P, t)=e^{\mathcal{T} t}\left(F_{0}-F\right),
$$

where $\mathcal{T}=\sigma^{2}$. Transforming $F$ from (7) into the above (10) we have

$$
\begin{gathered}
\left\{\begin{array}{l}
\mathcal{L} u \leq f, \\
u-u^{0} \leq 0, \\
(\mathcal{L} u-f) \cdot\left(u-u^{0}\right)=0,
\end{array}\right. \\
\left\{\begin{array}{l}
\mathcal{L} u=-u_{t}-\frac{\partial}{\partial P}\left(\varepsilon P^{2} \frac{\partial u}{\partial P}+\epsilon P u\right)+\xi u, \\
\xi=\vartheta+\mathcal{T}, \quad u^{0}=e^{\mathcal{T} t}\left(F_{0}-F^{0}\right), \quad f(p, t)=e^{\mathcal{T} t} L F_{0} .
\end{array}\right.
\end{gathered}
$$

Under the transformation (10), (8) and (9) change into

$$
u(0, t)=0=u\left(P_{\max }, t\right) \quad \text { and } \quad u(P, T)=u^{0}(P, T) .
$$

Let $\Omega=\left(0, P_{\max }\right)$, the $H_{\omega}^{1}(\Omega)$ is defined by

$$
H_{\omega}^{1}(\Omega)=\left\{v: v, P v_{P} \in L^{2}(\Omega)\right\},
$$

the norm $\|\cdot\|_{1, \omega}$ is defined by

$$
\|v\|_{1, \omega}^{2}=\int_{0}^{P_{\max }}\left(P^{2}\left(\frac{\partial v}{\partial P}\right)^{2}+v^{2}\right) d P .
$$

Suppose that

$$
H_{0, \omega}^{1}(\Omega)=\left\{v: v \in H_{\omega}^{1}(\Omega),\left.v\right|_{\partial \Omega}=0\right\}
$$


and

$$
\Lambda=\left\{v(t): v(t) \in H_{0, \omega}^{1}(\Omega), v(t) \leq u^{0}(t), \text { a.e. in }(0, T)\right\} .
$$

Apparently, $\Lambda$ is a subset of $H_{0, \omega}^{1}(\Omega)$. We write $v(\cdot, t)$ as $v(t)$, the independent time variable $t$ to avoid confusion in doing so. For any Hilbert space $H(\Omega)$, the norm of $L^{p}(0, T ; H(\Omega))$ such that

$$
\|v\|_{L^{p}(0, T ; H(\Omega))}=\left(\int_{0}^{T}\|v(\cdot, t)\|_{H}^{p} d t\right)^{1 / p} .
$$

Then

$$
\left(-\frac{\partial u}{\partial t}, v-u\right)+B(u, v-u ; t) \geq(f, v-u), \quad \text { a.e. in }(0, T),
$$

where $B(u, v ; t)$ is defined as

$$
B(u, v ; t)=\left(\varepsilon P^{2} \frac{\partial u}{\partial P}+\epsilon P u, \frac{\partial v}{\partial P}\right)+(\xi u, v), \quad \forall u, v \in H_{0, \omega}^{1}(\Omega) .
$$

Therefore, we can obtain the Theorem 1.

Theorem 1. Equations (13) and (14) are the variational form of the complementarity problem (11).

Proof. For $w \in \Lambda$ recalling the definition of $\Lambda$, we have

$$
w-u^{0} \leq 0, \quad \text { a.e. on } \Psi=\Omega \times(0, T) .
$$

As for Equation (11), we use $w-u^{0}$ to multiply both sides of the first inequality and then we have

$$
\left(-\frac{\partial u}{\partial t}, w-u^{0}\right)+B\left(u, w-u^{0} ; t\right) \geq\left(f, w-u^{0}\right), \quad \text { a.e. in }(0, T) .
$$

On one hand, if writing $w=\theta v+(1-\theta) u,(15)$ changes into

$$
\begin{aligned}
& \left(-\frac{\partial u}{\partial t}, \theta(v-u)\right)+B(u, \theta(v-u) ; t) \geq(f, \theta(v-u)) \\
& \quad-\left(\left(-\frac{\partial u}{\partial t}, u-u^{0}\right)+B\left(u, u-u^{0} ; t\right)-\left(f, u-u^{0}\right)\right), \quad \text { a.e. in }(0, T),
\end{aligned}
$$

on the other hand, it follows from (11) that

$$
\left(\mathcal{L} u-f, u-u^{0}\right)=0 .
$$

Consequently, it holds that

$$
\left(-\frac{\partial u}{\partial t}, u-u^{0}\right)+B\left(u, u-u^{0} ; t\right)-\left(f, u-u^{0}\right)=0 .
$$

Namely (17) simplifies as

$$
\left(-\frac{\partial u}{\partial t}, \theta(v-u)\right)+B(u, \theta(v-u) ; t) \geq(f, \theta(v-u)) .
$$

Then there holds 


$$
\left(-\frac{\partial u}{\partial t}, v-u\right)+B(u, v-u ; t) \geq(f, v-u), \quad \text { a.e. in }(0, T) .
$$

To sum up, we prove this Theorem.

Lemma 1. We set a positive constant $c$, such that for arbitrary $v, w \in H_{0, \omega}^{1}(\Omega)$, it holds that

$$
B(v, v ; t) \geq c\|v\|_{1, \omega}^{2} \quad \text { and } \quad|B(v, w ; t)| \leq C\|v\|_{1, \omega}\|w\|_{1, \omega} .
$$

Proof. For arbitrary $v \in H_{0, \omega}^{1}(\Omega)$, we obtain

$$
\int_{0}^{P_{\max }} \epsilon P v v^{\prime} d P=-\frac{1}{2} \int_{0}^{P_{\max }} \epsilon v^{2} d P .
$$

Combining with $B(\cdot, \cdot ; t)$ in $(14)$, we obtain

$$
\begin{aligned}
B(v, v ; t) & =\left(\varepsilon P^{2} v^{\prime}+b P v, v^{\prime}\right)+(\xi v, v) \\
& =\left(\varepsilon P^{2} v^{\prime}, v^{\prime}\right)+\left(\left(\rho+\epsilon+\mathcal{T}-\frac{\epsilon}{2}\right), v\right) \\
& =\left(\varepsilon P^{2} v^{\prime}, v^{\prime}\right)+\frac{1}{2}\left(\left(3 \rho+2 \mathcal{T}-\sigma^{2}\right) v, v\right) \\
& \geq \frac{1}{2} \min \left(\sigma^{2}, 3 \rho\right)\left[\left(P^{2} v^{\prime}, v^{\prime}\right)+(v, v)\right] \\
& =c\|v\|_{1, \omega}^{2} .
\end{aligned}
$$

Now, for arbitrary $v, w \in H_{0, \omega}^{1}(\Omega)$, it yields

$$
\begin{aligned}
|B(v, w ; t)|= & \left|\left(\varepsilon P^{2} v^{\prime}, w^{\prime}\right)+\left(\epsilon P v, w^{\prime}\right)+(\xi v, w)\right| \\
\leq & \left|\left(\varepsilon P^{2} v^{\prime}, w^{\prime}\right)+(\xi v, w)\right|+\left|\left(\epsilon P v, w^{\prime}\right)\right| \\
\leq & \left|\int_{0}^{P_{\max }}\left(\varepsilon P^{2} v^{\prime} w^{\prime}+\xi v w\right) d P\right|+\left|\int_{0}^{P_{\max }} \epsilon P v^{\prime} w d P\right| \\
\leq & C\left(\left(\int_{0}^{P_{\max }} P^{2} v^{\prime 2} d P\right)^{\frac{1}{2}}\left(\int_{0}^{P_{\max }} P^{2} w^{\prime 2} d P\right)^{\frac{1}{2}}\right. \\
& \left.+\left(\int_{0}^{P_{\max }} v^{2} d P\right)^{\frac{1}{2}}\left(\int_{0}^{P_{\max }} w^{2} d P\right)^{\frac{1}{2}}+\left|\int_{0}^{P_{\max }} v w d P\right|\right) \\
\leq & C\left(\left(\int_{0}^{P_{\max }}\left(P^{2} v^{\prime 2}+v^{2}\right)\right)^{\frac{1}{2}}\left(\int_{0}^{P_{\max }}\left(P^{2} w^{\prime 2}+w^{2}\right)\right)^{\frac{1}{2}}+\|v\|_{0, \omega}\|w\|_{0, \omega}\right) \\
\leq & C\left(\|v\|_{1, \omega}\|w\|_{1, \omega}+\|v\|_{0, \omega}\|w\|_{0, \omega}\right) \\
\leq & C\|v\|_{1, \omega}\|w\|_{1, \omega} .
\end{aligned}
$$

In conclusion, the proof is finished.

Theorem 2. Equations (13) and (14) have a unique solution.

Proof. It follows from Lemma 1 that Equations (13) and (14) exists a unique solution.

Next considering the nonlinear variable inequality, namely, find $u_{h} \in H_{0, \omega}^{1}(\Omega)$ such that

$$
\left(-\frac{\partial u_{h}}{\partial t}, v-u_{h}\right)+B\left(u_{h}, v-u_{h} ; t\right)+s(v)-s\left(u_{h}\right) \geq\left(f, v-u_{h}\right) \quad \text { a.e. in }(0, T),
$$


and

$$
s(v)=\frac{h k}{k+1}\left[v-u^{0}\right]_{+}^{\frac{k+1}{k}}, \quad k>0, \quad h>1,
$$

Theorem 3. Equation (18) has a unique solution.

Proof. It follows from Lemma 1 that the bilinear operator $B$ possesses the properties of coerciveness and continuity. By force of (19), s owns the property of semi-continuity. Hence, the properties of stability of $B$ and $s$ guarantee the uniqueness of the solution of (18).

Since $s(v)$ is differentiable so (18) can be change into: Find $u_{h} \in H_{0, \omega}^{1}(\Omega)$ for arbitrary $v \in H_{0, \omega}^{1}(\Omega)$, there exists

$$
\left(-\frac{\partial u_{h}}{\partial t}, v\right)+B\left(u_{h}, v ; t\right)+\left(s^{\prime}\left(u_{h}\right), v\right) \geq(f, v) \text { a.e. in }(0, T),
$$

and

$$
s^{\prime}(v)=h\left[v-u^{0}\right]_{+}^{\frac{1}{k}} .
$$

Pointing out that (20) and (21) to (13), (20) and (21), there holds that

$$
\mathcal{L} u_{h}+h\left[u_{h}-u^{0}\right]_{+}^{\frac{1}{k}}=f, \quad(P, t) \in \Psi,
$$

follows from the initial boundary conditions

$$
\left.u_{h}(P, t)\right|_{\partial \Omega}=0 \quad \text { and } \quad u_{h}(P, t)=u^{0}(P, t) .
$$

Giving a description that if $k=\frac{1}{2}$, the penalty method corresponds to the second penalty method.

Now, we are in the position to investigate that the convergence rates of $u_{h}$ to $u$ as $h \rightarrow \infty$. Let's start with the following Lemma [6,22].

Lemma 2. Let $u_{h}$ be the solution of (13) and (14) and if $u_{h} \in L^{p}(\Omega \times(0, T))$, then there holds

$$
\begin{aligned}
& \left\|\left[u_{h}-u^{0}\right]_{+}\right\|_{L^{p}(\Psi)} \leq \frac{C}{h^{k}}, \\
& \left\|\left[u_{h}-u^{0}\right]_{+}\right\|_{L^{\infty}\left(0, T ; L^{2}(\Omega)\right)}+\left\|\left[u_{h}-u^{0}\right]_{+}\right\|_{L^{2}\left(0, T ; H_{0}^{1}(\Omega)\right)} \leq \frac{C}{h^{k / 2}},
\end{aligned}
$$

Lemma 3. Let $u_{h}$ be the solution of (20) and (21) and if $u_{h} \in L^{p}(\Psi)$, then there holds

$$
\begin{aligned}
& \left\|\left[u_{h}-u^{0}\right]_{+}\right\|_{L^{p}(\Psi)} \leq \frac{C}{h^{k / 2}}, \\
& \left\|\left[u_{h}-u^{0}\right]_{+}\right\|_{L^{\infty}\left(0, T ; L^{2}(\Omega)\right)}+\left\|\left[u_{h}-u^{0}\right]_{+}\right\|_{L^{2}\left(0, T ; H_{0, \omega}^{1}(\Omega)\right)} \leq \frac{C}{h^{k / 2}}
\end{aligned}
$$

where $p=1+1 / k$.

Based on Lemma 2 and 3, the solution of (20) and (21) is convergent to that of (13) and (14) at the order $O\left(h^{-\frac{k}{2}}\right)$ as $h \rightarrow \infty$.

Lemma 4. Let $u$ and $u_{h}$ be the solutions to (13), (14), (20) and (21), respectively. If $u_{h} \in L^{p}(\Psi)$ and $\frac{\partial u}{\partial t} \in L^{k+1}(\Psi)$, then

$$
\left\|u-u_{h}\right\|_{L^{\infty}\left(0, T ; L^{2}(\Omega)\right)}+\left\|u-u_{h}\right\|_{L^{2}\left(0, T ; H_{0, \omega}^{1}(\Omega)\right)} \leq \frac{C}{h^{k / 2}},
$$




\section{Discussion}

In this section, we will provide an empirical study by using the finite volume method. We set $\theta=0.5, h=10$ and $k=4$.

Now, we are in the position to carry out an empirical study where we take Wanzhou District of Chongqing City as an example to strengthen our theoretical analysis. We find that the water price in Wanzhou The district is 1000-2500 yuan per ton. Based on the new irrigation technology, the water-saving efficiency is increased to 30 percent. Then we choose $a^{0}=380 \times 30 \%=114$ million liters per year where the total agricultural water consumption in Wanzhou District is 380 million liters per year. In addition, the total operating cost and the total investment cost of agricultural water management in Wanzhou districts are 64,050 and 91,500 thousand yuan, respectively. So, we choose $Q=64,050$ and $I=91,500$. According to [19], some important invariant parameters are given in Table 1 .

Table 1. European real option with parameters for (2).

\begin{tabular}{ccccc}
\hline$P_{\max }=2500$ & $Q=64,050$ & $I=91,500$ & $T=1$ & $\alpha=0.03$ \\
\hline$a^{0}=114$ & $\sigma=0.21$ & $\gamma=0.06$ & $\rho=0.06$ & $\delta=0.04$ \\
\hline
\end{tabular}

We first here to illustrate the convergence rate. Putting $\left(0, P_{\max }\right)$ and $(0, T)$ into 49 $\times 49$ sub-intervals to solve with the parameters from the Table 1 , we obtain the result as shown in the Figure 1.

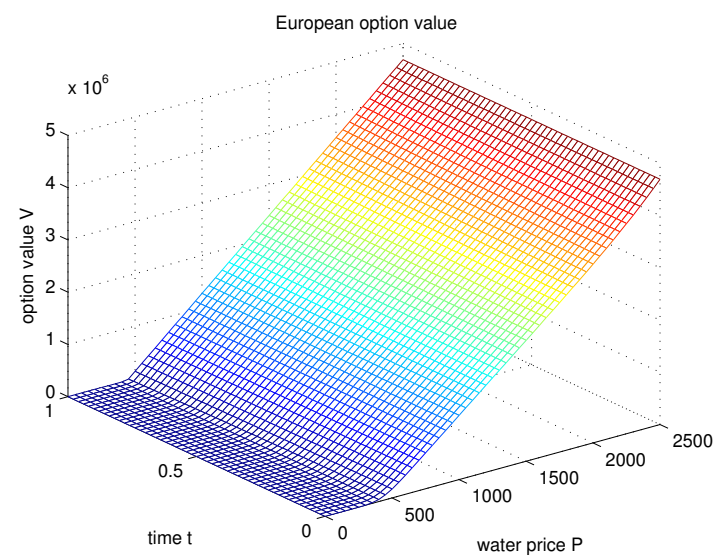

Figure 1. The values of European real option follows from Table 1.

The solution is provided on $N=2^{16}$ and $M=2^{15}$, then we draw Table 2, and the rate is given by

$$
\text { rate }=\frac{\left\|F_{h}^{\Delta t}-F\right\|_{\infty}}{\left\|F_{h / 2}^{\Delta t / 2}-F\right\|_{\infty}}
$$

and the error estimates via

$$
\left\|F-F_{h}\right\|_{\infty} \equiv 0.2685 h^{1.9724},
$$

that tells

$$
\left\|F-F_{h}\right\|_{\infty} \leq C h^{2}
$$


Table 2. The errors of the $L^{\infty}$-norm.

\begin{tabular}{cccccc}
\hline Mesh & L $^{\infty}$-Norm & Ratio & Mesh & L $^{\infty}$-Norm & Ratio \\
\hline $2^{5} \times 2^{4}$ & 1245.4000 & & $2^{11} \times 2^{10}$ & 0.8553 & 1.9681 \\
$2^{6} \times 2^{5}$ & 998.1352 & 1.2477 & $2^{12} \times 2^{11}$ & 0.6930 & 1.2342 \\
$2^{7} \times 2^{6}$ & 83.4338 & 11.9632 & $2^{13} \times 2^{12}$ & 0.0561 & 12.3603 \\
$2^{8} \times 2^{7}$ & 74.1436 & 1.1253 & $2^{14} \times 2^{13}$ & 0.0283 & 1.9852 \\
$2^{9} \times 2^{8}$ & 42.5721 & 1.7416 & $2^{15} \times 2^{14}$ & 0.0140 & 2.0213 \\
$2^{10} \times 2^{9}$ & 1.6833 & 12.9047 & $2^{16} \times 2^{15}$ & 0.0012 & 11.9687 \\
\hline
\end{tabular}

Similar to the European real option, we adopt the similar data, of which the source is the same as the European real option in Table 3, to describe the numerical experiments to the American real option [19].

Table 3. The parameters for (2) of American real option.

\begin{tabular}{ccccc}
\hline$P_{\max }=2500$ & $Q=64,050$ & $I=91,500$ & $T=1$ & $\alpha=0.03$ \\
\hline$a^{0}=114$ & $\sigma=0.21$ & $\gamma=0.06$ & $\rho=0.06$ & $\delta=0.04$ \\
\hline
\end{tabular}

We plot the profiles of the value of $\Delta$ showed in Figures 2 and 3. In addition, we provide the optimal exercise boundary in Figure 4 and we draw the optimal exercise boundaries for different parameters in Figures 5-9 where we can evaluate how parameters affect the timing of investment.

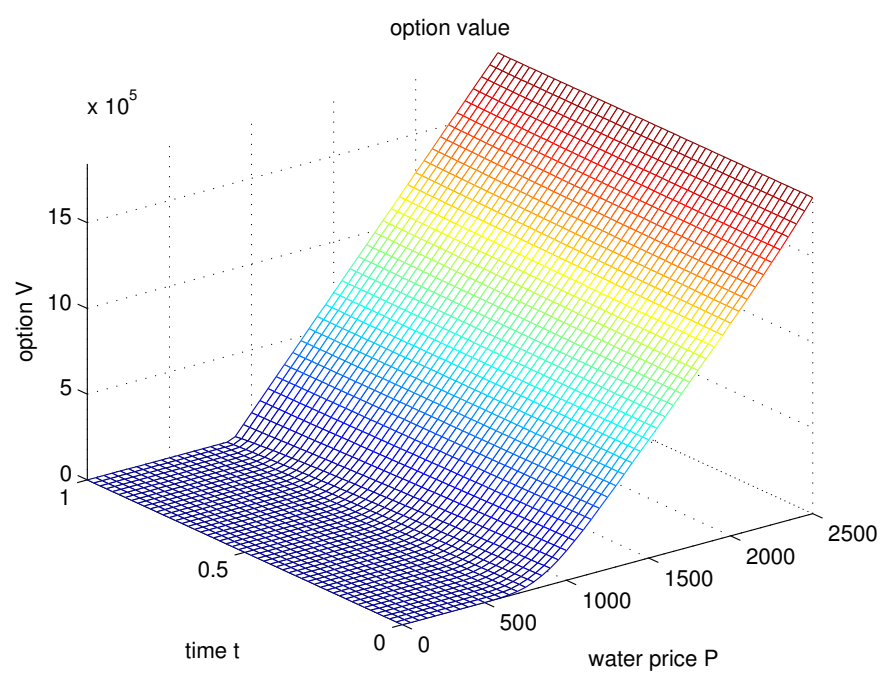

Figure 2. The values of American real option follows from Table 3. 


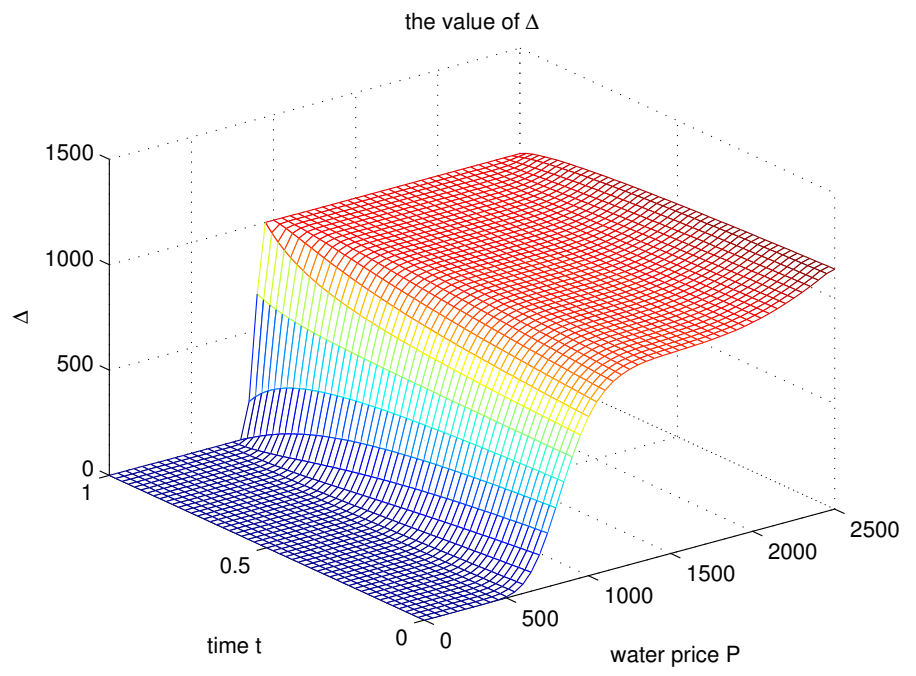

Figure 3. The value of $\Delta$ for Table 3 .

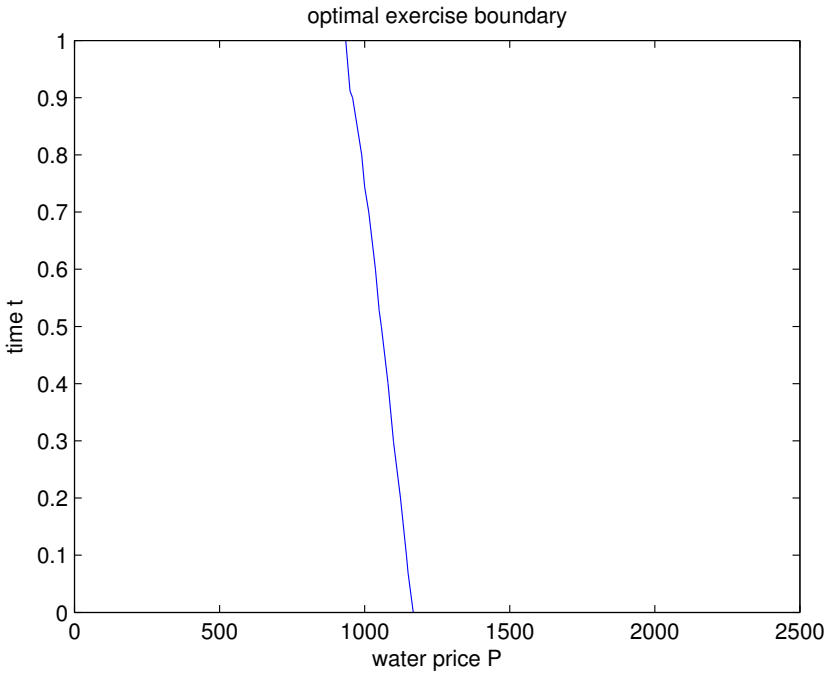

Figure 4. The boundary of optimal exercises follows form Table 3.

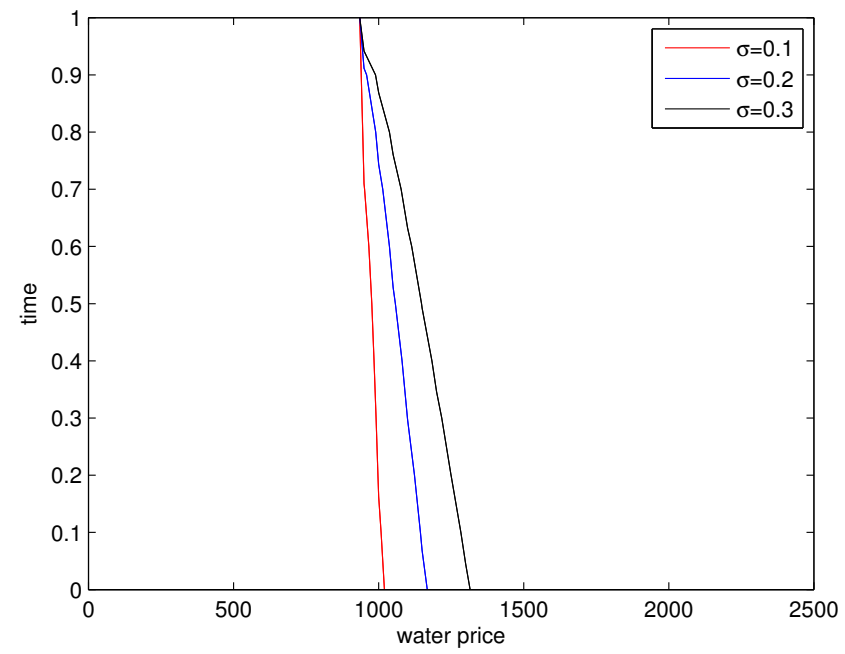

Figure 5. Comparison based on different $\sigma$ for Table 3 . 


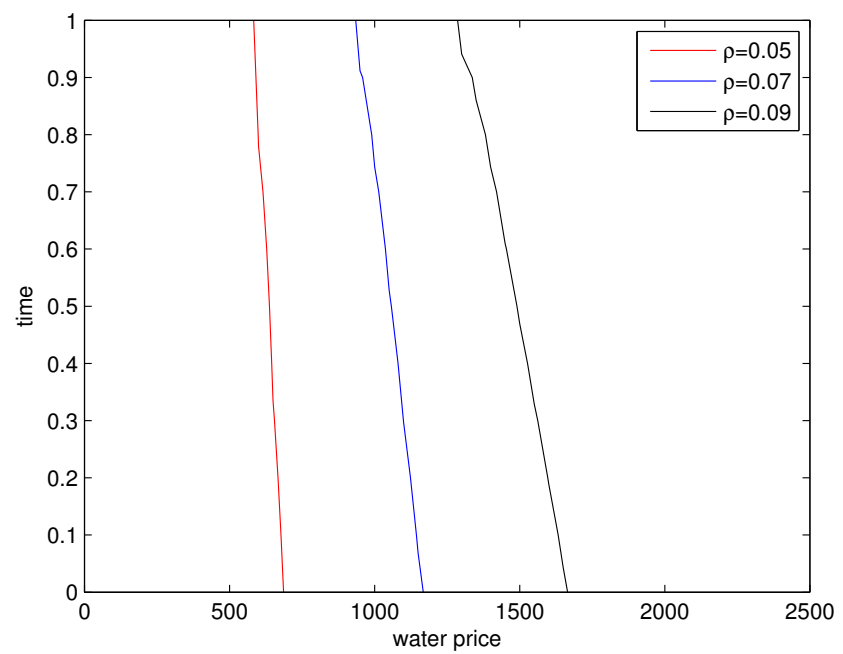

Figure 6. Comparison based on different $\rho$ for Table 3 .

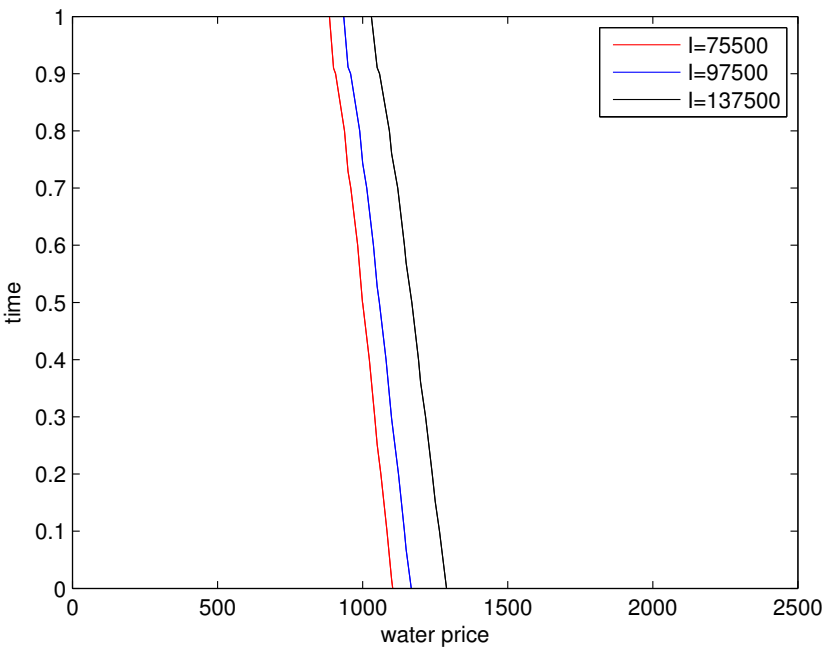

Figure 7. Comparison based on different $I$ for Table 3.

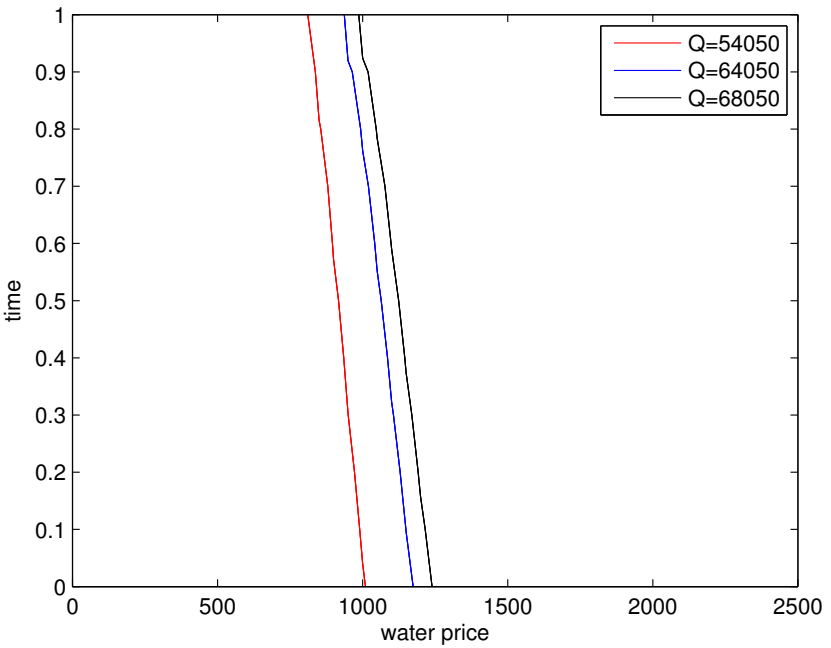

Figure 8. Comparison based on different $Q$ for Table 3 . 


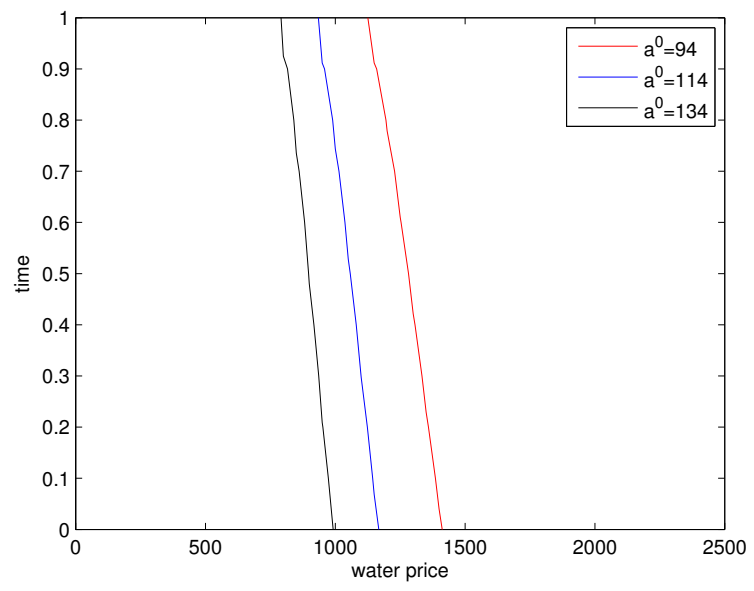

Figure 9. Comparison based on different $a^{0}$ for Table 3 .

Obviously, from Figures 5-9, we require something as follows: the non-investment area becomes larger and the investment area becomes smaller. Beyond that, the boundary is less sensitive to $Q$ and $a^{0}$ than $\sigma, \rho$, and $I$. In addition, compared with other parameters, the subjective discount rate has the greatest impact on the investment boundary.

Now, we take Kaizhou District adjacent to Wanzhou District for the experiment object to the American real option. We find that the water price in Kaizhou District is 1000-2500 yuan per ton. The water-saving efficiency is increased to 30 percent due to the new irrigation technology. Then we choose $a^{0}=280 \times 30 \%=84$ million liters per year where the total agricultural water consumption in Kaizhou District is 280 million liters per year. Besides, the total operating cost and the total investment cost of agricultural water management in the Kaizhou District are 11,910 and 39,700 thousand yuan, respectively. Thus, we choose $Q=11,910$ and $I=39,700$. According to [19], some important invariant parameters are given in Table 4.

Table 4. The parameters for (4) of American real option with .

\begin{tabular}{ccccc}
\hline$P_{\max }=2500$ & $Q=11,910$ & $I=39,700$ & $T=1$ & $\alpha=0.02$ \\
\hline$a^{0}=84$ & $\sigma=0.2$ & $\gamma=0.07$ & $\rho=0.07$ & $\delta=0.05$ \\
\hline
\end{tabular}

Similar treatment which divided $\left(0, P_{\max }\right)$ and $(0, T)$. The derivative of $V(P)$ concerning $P$ under circumstances of (4), thus we draw the real option value in Figure 10 while the value of $\Delta$, and we draw the Figures 11 and 12. Furthermore, we draw the optimal exercise boundaries for different parameters in Figures 13-17, respectively.

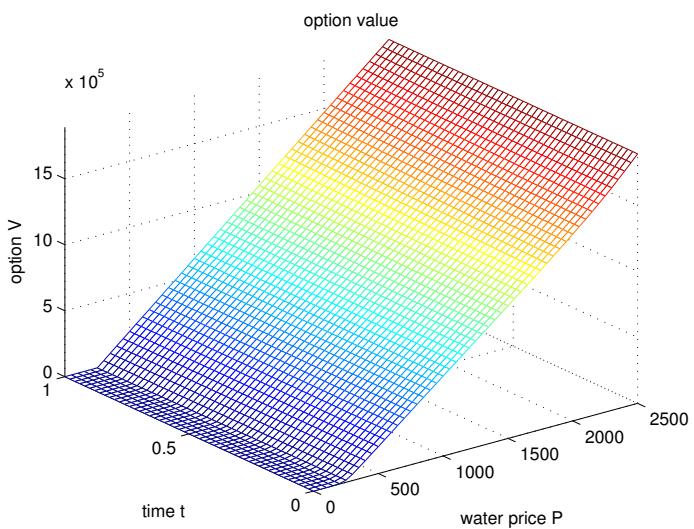

Figure 10. The values of American real option follows from Table 4. 


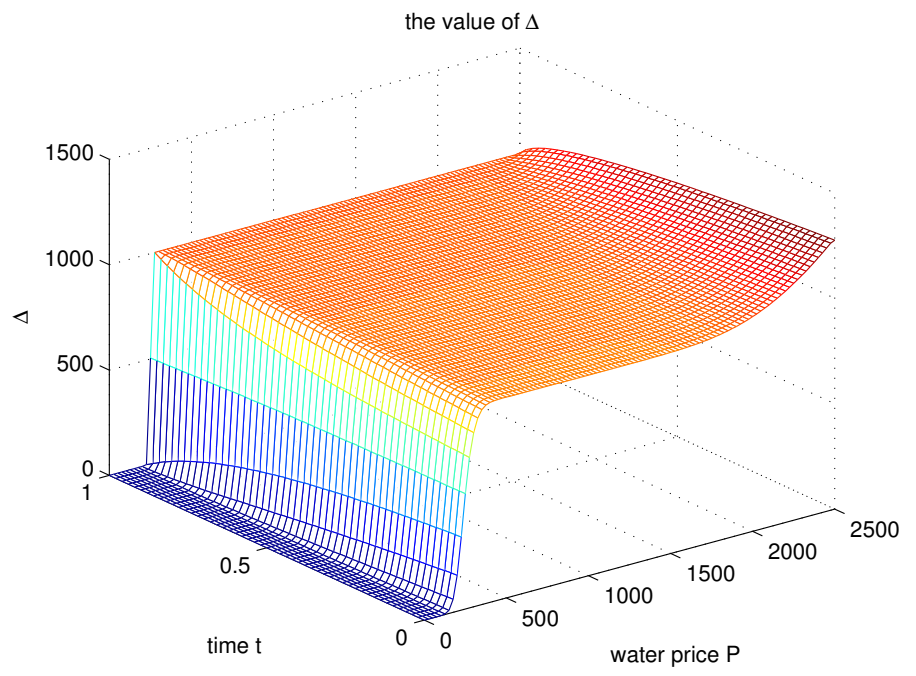

Figure 11. The value of $\Delta$ for Table 4 .

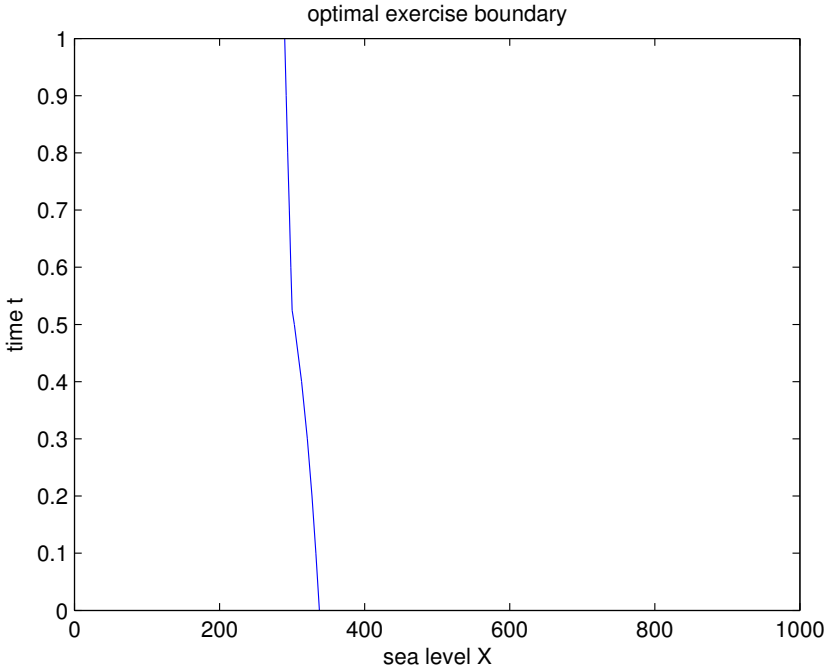

Figure 12. The optimal exercises boundary for Table 4 .

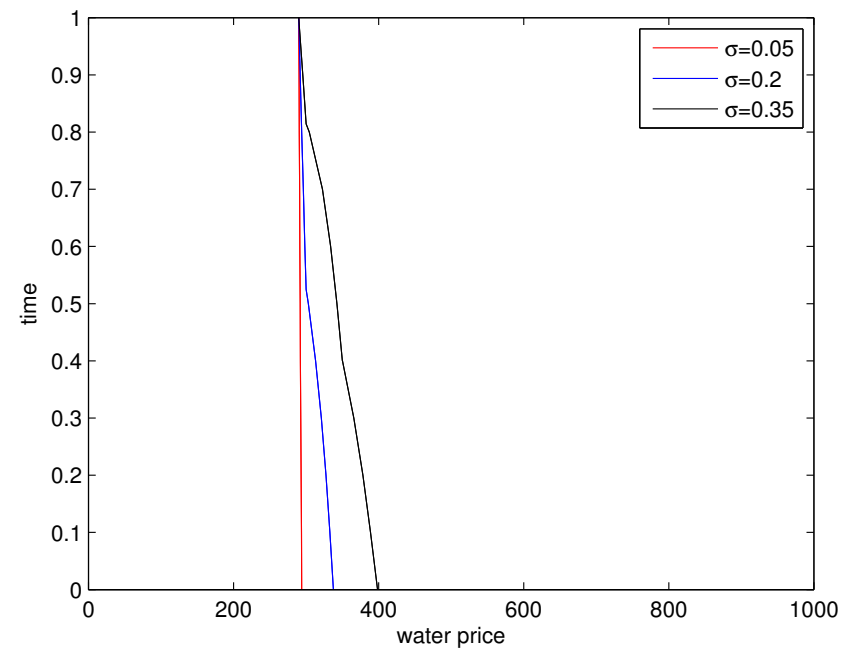

Figure 13. Comparison based on different $\sigma$ for Table 4 . 


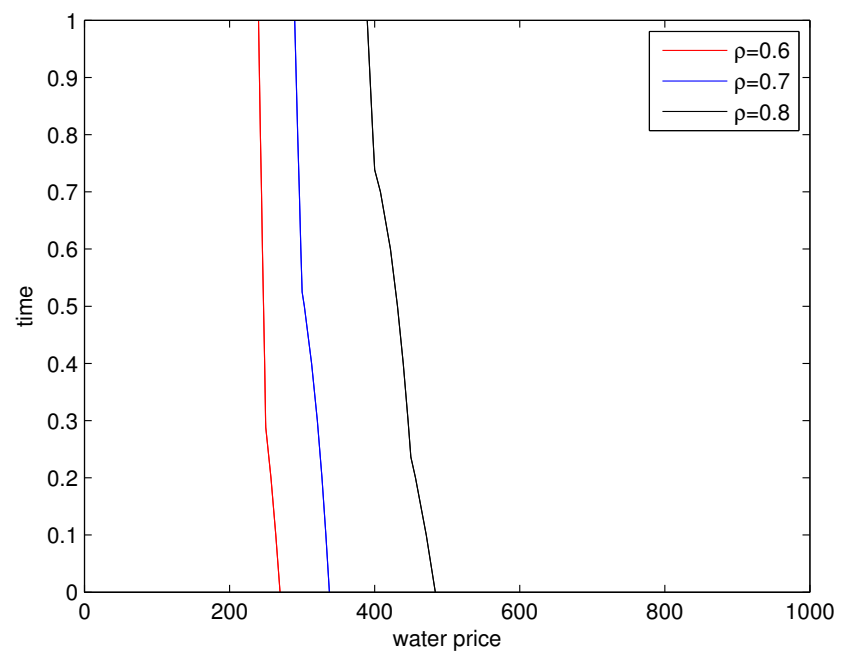

Figure 14. Comparison based on different $\rho$ for Table 4 .

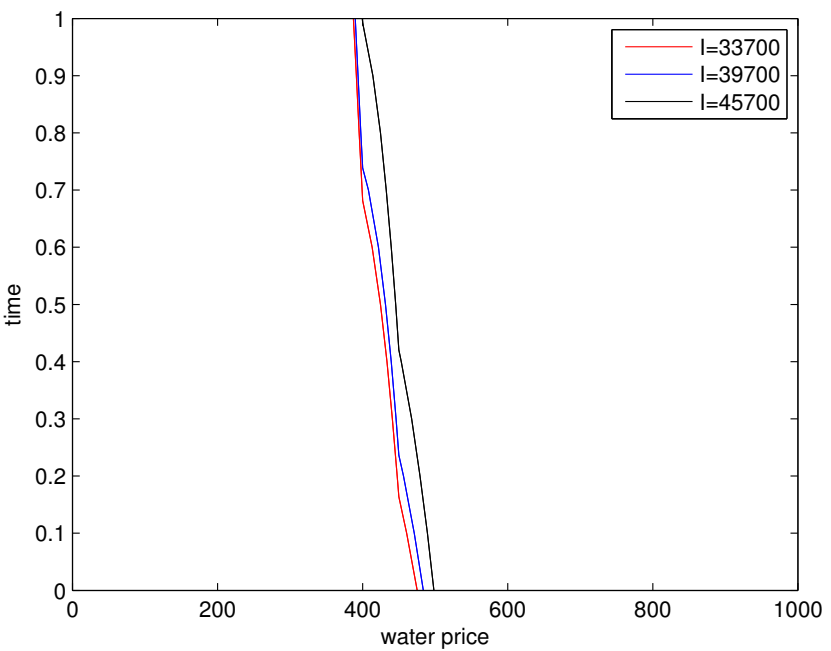

Figure 15. Comparison based on different $I$ for Table 4 .

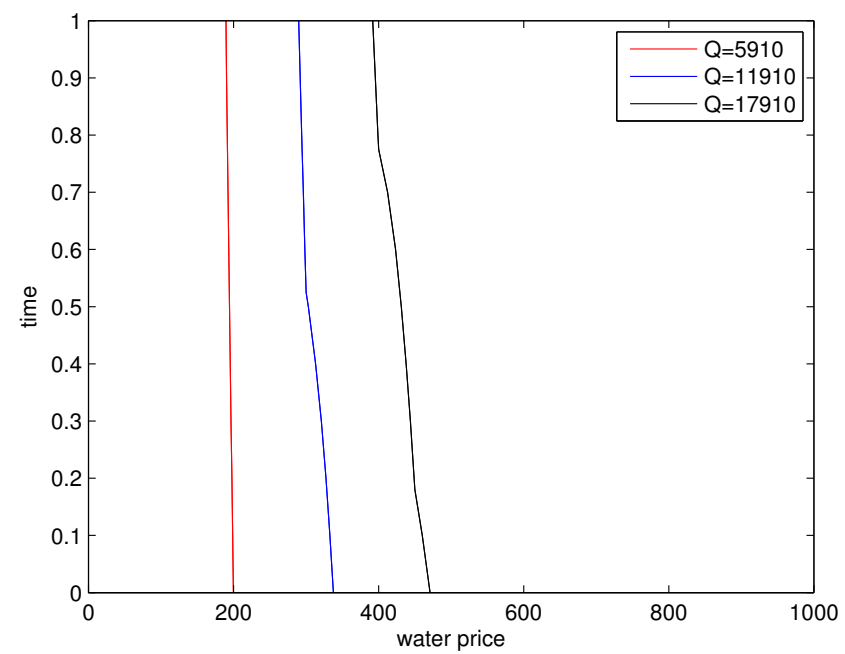

Figure 16. Comparison based on different $Q$ for Table 4 . 


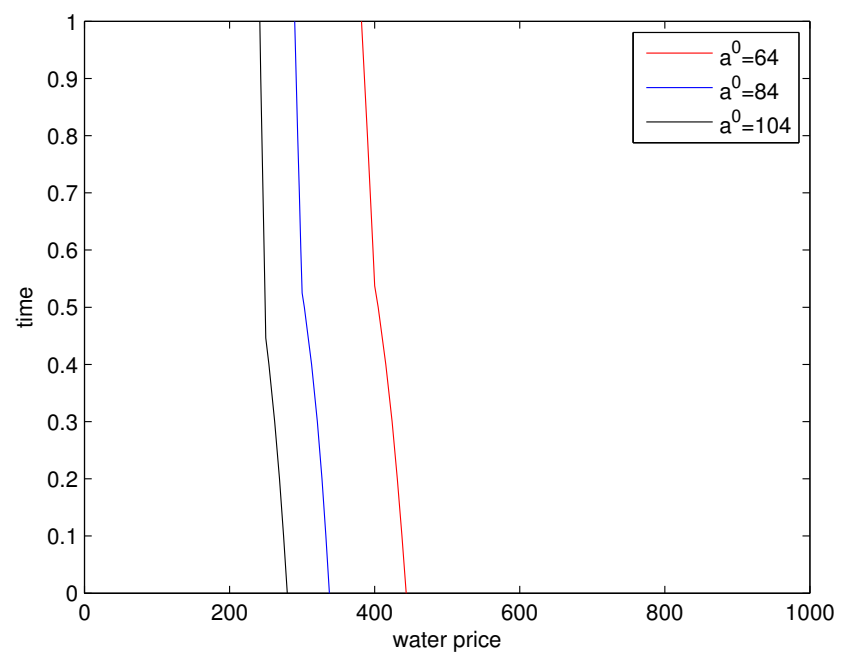

Figure 17. Comparison based on different $a^{0}$ for Table 4 .

Comparing Figures 5-9 with Figures 13-17, we debug the impact of different parameters on investment boundaries, we still require that suspending options will affect the timing of investment for decision-making problems.

The reason why we need to study the water management of water irrigation is that imperfect irrigation system that leads to serious waste of water resources. By using real options model to study water management and empirical analysis of measured data of water irrigation in some areas, we find that this model is not only effective and practical, but also can provide decision-making reference for water irrigation management.

The empirical examples of real options on water management can be found that this model has positive significance in management and economics. Farmland irrigation infrastructure is seriously inadequate. The existing facilities are generally aging and damaged with lower water supply capacity, which are far from meeting the production needs of residents. It is necessary to take effective measures to construct and improve farmland irrigation facilities to promote the stability and the prosperity of migrants and the stable development of the social economy in the reservoir area where improvement measures should pay attention to local conditions, long-term effect, mainly small water supply projects.

\section{Conclusions}

In this paper, we propose a model about water management to analysis the choice of investment in water savings. Ultimately, it is of vital importance to manage water efficiency from our model numerical examples. Water savings in irrigation-based on water resources and the patterns of agricultural water demand can effectively save water resources. In addition, the investment timing is influenced by the water price. then we use a method to conduct a model in water management by a linear parabolic variational inequality. Beyond that, we obtained the vary type boundary conditions. And switch the linear parabolic variational inequalities into nonlinear parabolic equations via a method called the power penalty approach. Hereafter, we found that the solutions are converges to the rate of order $O\left(\lambda^{-\frac{k}{2}}\right)$.

Author Contributions: Z.L. and X.W. have participated in the sequence alignment and drafted the manuscript. F.C. and F.H. have made substantial contributions to conception and design. All authors have read and agreed to the published version of the manuscript.

Funding: This work is supported by National Science Foundation of China (11201510), National Social Science Fund of China (19BGL190), China Postdoctoral Science Foundation (2017T100155, 2015M580197), Innovation Team Building at Institutions of Higher Education in Chongqing (CXTDX- 
201601035), Chongqing Research Program of Basic Research and Frontier Technology (cstc2019jcyjmsxmX0280) and Scientific and Technological Research Program of Chongqing Municipal Education Commission (KJZD-K202001201), Youth Innovative Talents Project (Natural Science) of research on humanities and social sciences in Guangdong normal university (2017KQNCX265), Hunan Provincial Education Department of China (18C0196).

Institutional Review Board Statement: Not applicable.

Informed Consent Statement: Not applicable.

Data Availability Statement: Not applicable.

Conflicts of Interest: The authors declare no conflict of interest.

\section{References}

1. Lin, A.; Miglietta, P.P.; Toma, P. Did carbon emission trading system reduce emissions in china? An integrated approach to support policy modeling and implementation. Energy Syst. 2021, 13, 1-23.

2. Miglietta, P.P.; Giove, S. An optimization framework for supporting decision making in biodiesel feedstock imports: Water footprint vs. import costs. Cological Indic. Integr. Monit. Assess. Manag. 2018, 85, 1231-1238. [CrossRef]

3. Hongjie, P.; Lei, H.; Xuesong, Z. Effects of Landscape Positions and Landscape Types on Soil Properties and Chlorophyll Content of Citrus in a Sloping Orchard in the Three Gorges Reservoir Area, China. Sustainability 2021, 13, 4288.

4. George, S.; Shareen, J. Bridges over Troubled Waters? The Political Economy of Public-Private Partnerships in the Water Sector. Sustainability 2021, 13, 10127.

5. Fu, R.; Li, C. Water quality investigation of centralized water supply in wanzhou migrant resettlement area in the Three Gorges Reservoir Area. J. Environ. Health 2009, 26, 900-912.

6. Zhang, S.; Wang, X. Modeling and computation of water management by real options. J. Ind. Manag. Optim. 2018, 14, 81-103. [CrossRef]

7. Michailidis, A.; Mattas, K. A socioeconomic valuation of an irrigation system project based on real option analysis approach. Water Resour. Manag. 2009, 23, 1989-2001. [CrossRef]

8. Bagatin, R.; Klemes, J. Conservation and improvements in water resource management: A global challenge. J. Clean. Prod. 2014, 77, 3943-3955. [CrossRef]

9. France, R. Exploring the bonds and boundaries of water management in a global context. J. Clean. Prod. 2013, 60, 1-3. [CrossRef]

10. Carey, J.; Zilberman, D. A Model of Investment under Uncertainty: Modern Irrigation Technology and Emerging Markets in Water. Am. J. Agric. Econ. 2002, 84, 171-183. [CrossRef]

11. Kobari, L.; Jaimungal, S. A real options model to evaluate the effect of environmental policies on the oil sands rate of expansion. Energy Econ. 2014, 45, 155-165. [CrossRef]

12. Chorn, L.; Shokhor, S. Real options for risk management in petrolem development investments. Energy Econ. 2006, 48, 489-505. [CrossRef]

13. Wang, T.; Neufville, R. Building real options into physical systems with stochastic mixed integer programming. In Proceedings of the 8th Annual Real Options International Conference, Montréal, QC, Canada, 17-19 June 2004; Volume 47, pp. 23-32.

14. Huang, F.; Lu, Z.; Li, L.; Wu, X. Numerical simulation for european and american option of risks in climate change of three gorges reservoir area. J. Numer. Math. 2020, 24, 537-548. [CrossRef]

15. Wasylewicz, A. Analysis of the Power Penalty Method for American Options Using Viscosity Solutions; University of Oslo: Oslo, Norway, 2008.

16. Han, W.; Reddy, B. On the finite element method for mixed variational inequalities arising in elastoplasticity. SIAM J. Numer. Anal. 1995, 23, 1778-1807. [CrossRef]

17. Huang, Z.; Han, L. Effects of land use patterns on stream water quality: A case study of a small-scale watershed in the Three Gorges Reservoir Area, China. Environ. Sci. Pollut. Res. 2016, 23, 3943-3955. [CrossRef] [PubMed]

18. He, Y. Real Options in the Energy Markets. Ph.D. Thesis, University of Twente, Enschede, The Netherlands, 2007.

19. McClintock, A. Investment in Irrigation Technology: Water Use Change, Public Policy and Uncertainty. Coop. Res. Irrig. Futur. 2014, 24, 678-681.

20. Sarkar, S. The effect of mean reversion on investment under uncertainty. J. Econ. Dyna. Con. 2004, 28, 377-396. [CrossRef]

21. Samuelson, P. Proof that properly anticipated prices uctuate randomly. Numer. Math. 2007, 106, 1-40.

22. Chang, S.; Wang, J.; Wang, X. A fitted finite volume method for real option valuation of risks in climate change. Comput. Math. Appl. 2015, 70, 1198-1219. [CrossRef] 